Article

\title{
Integrated Environmental Risk Assessment of Major Accidents in the Transport of Hazardous Substances
}

\author{
Ales Bernatik ${ }^{1, *(\mathbb{D}}$, David Rehak ${ }^{1}$, Valerio Cozzani ${ }^{2} \mathbb{D}$, Pavel Foltin ${ }^{3}$, Jarmil Valasek ${ }^{4}$ and Frantisek Paulus $^{4}$ \\ 1 Faculty of Safety Engineering, VSB-Technical University of Ostrava, 70030 Ostrava, Czech Republic; \\ david.rehak@vsb.cz \\ 2 Laboratory of Industrial Safety and Environmental Sustainability-DICAM, University of Bologna, \\ 40126 Bologna, Italy; valerio.cozzani@unibo.it \\ 3 Faculty of Military Leadership, University of Defence, 66210 Brno, Czech Republic; pavel.foltin@unob.cz \\ 4 Population Protection Institute, 53341 Lazne Bohdanec, Czech Republic; jarmil.valasek@ioolb.izscr.cz (J.V.); \\ frantisek.paulus@ioolb.izscr.cz (F.P.) \\ * Correspondence: ales.bernatik@vsb.cz; Tel.: +420-597-322-833
}

Citation: Bernatik, A.; Rehak, D.; Cozzani, V.; Foltin, P.; Valasek, J.; Paulus, F. Integrated Environmental Risk Assessment of Major Accidents in the Transport of Hazardous Substances. Sustainability 2021, 13, 11993. https://doi.org/10.3390/ su132111993

Academic Editors: Chunjiang An and Marc A. Rosen

Received: 25 August 2021

Accepted: 26 October 2021

Published: 29 October 2021

Publisher's Note: MDPI stays neutral with regard to jurisdictional claims in published maps and institutional affiliations.

Copyright: (c) 2021 by the authors. Licensee MDPI, Basel, Switzerland. This article is an open access article distributed under the terms and conditions of the Creative Commons Attribution (CC BY) license (https:/ / creativecommons.org/licenses/by/ $4.0 /)$.

\begin{abstract}
At present, the environmental risk assessment of major accidents is mainly carried out for stationary risk sources. Only marginal attention is paid to mobile risk sources, while the currently available methodologies require a relevant expertise and time for their application, which is only partially possible in most scenarios. In the present study, an integrated approach to environmental risk assessment in the transport of hazardous substances (iTRANSRISK) was developed. The approach proposed is based on the principle of index-based assessment of leakage scenarios involving toxic and flammable substances during transport, in the context of indexing environmental vulnerability. The key point of the method is the conversion of local-specific data concerning the risk potential of the transported substance, the consequences and the probability of a major accident, and environmental vulnerability assessment into a single entity. The created integral approach is proposed for the needs of carriers of the hazardous substances and the state administration bodies. The proposed approach is determined for the screening risk assessment at the beginning of the process of the planning a suitable transport routes and the results are for information only. An example of the application of the iTRANSRISK integrated approach is demonstrated considering an explosion scenario following a propane tanker leak $(18 \mathrm{t})$ in a forested area, with moderately susceptible soils and no surface water or groundwater affected.
\end{abstract}

Keywords: integrated approach; risk assessment; major accident; environmental damage; vulnerability assessment; transport of hazardous substances

\section{Introduction}

Industrial enterprises produce and ship significant quantities of hazardous substances that pose a risk to the environment, mainly related to toxicity, flammability and explosiveness. The rapid increase in the transport of hazardous substances requires risk assessment and management. Accidents involving the transport of hazardous substances are occurring ever more frequently throughout the world, with serious consequences for the population, property and the environment.

Hazardous substances can be characterized as substances which, if released into the environment, cause significant material and environmental damage, injury or even death to the persons affected [1]. The transport of hazardous substances poses a major risk to the population and the environment. With the amount of cargo transported, congestion along the transport routes and the potential for emergencies, transport accidents cannot be foreseen. However, conditions can be created that reduce the impact of such accidents, ranging from establishing and complying with laws, regulations, ordinances and technical standards to ensure the safety of equipment, to identifying potential incidents, analyzing, 
evaluating and suggesting improvements and training on how to manage the occurrence and progress of emergency situations.

At present, risk assessment of major accidents involving mobile sources of risk is carried out only sporadically, mostly using only simple mathematical models. The incidence of major accidents involving the transport of hazardous substances is steadily increasing, and accidents or environmental pollution can cause serious injuries in densely populated areas. Nevertheless, risk assessment in the field of transport of hazardous substances is not a legislative requirement in the European Union and is excluded from Directives requiring the control of major accidents hazards in stationary installations [1].

In general, the first step required in a risk-reduction process is risk analysis [2]. Risk analysis is usually understood as the process of defining threats, their likelihood of occurrence and impact (i.e., determining the risks and their severity). For the purpose of the present study, risk analysis represents a critical basis for the process of eliminating risks in the transport of hazardous substances.

Hazardous chemical transportation risk analysis was addressed by Zhang and Zhao [3], who summarized the probability and severity of accidents in Shanghai using GIS. A similar study using TRAT-GIS software was conducted in Sicily [4], and the results in the form of individual risks were displayed on a map. A quantitative analysis of the environmental risks of rail transport of a group of light anhydrous liquids commonly transported by rail in North America was also performed using GIS [5]. A conceptual tool for the identification and determination of environmental risks and a risk management principle for the transportation of hazardous goods by rail was proposed by Zelenko et al. [6]. A technical report by Sandia National Laboratories [7] evaluated the risk acceptability criteria for the transportation of hazardous materials in the United States.

A few other studies addressed specifically the quantification of the risk for the environment due to accidents in the transportation of hazardous substances. An approach to the quantification of risks to environmental components along transport routes using habitat values was proposed by Saska [8]. Similarly, the study by Macias and Gadziński [9] assessed the environmental value of individual areas that are at risk from road transport of hazardous substances. In the Finnish coastal area, the environmental hazard potential of 15 transported chemicals was assessed using a scoring method developed for accidents [10].

Conca et al. [11] analyzed the interactions between traffic flow and accident frequency, and an integrated safety assessment approach was proposed on this basis. The study of Dvorak et al. [12] developed a qualitative approach to environmental risk assessment (QAERA) in transport, which is based on the six pillars of safety and security. Other more specific impacts on the environment were considered in specific studies, such as the prevention and minimization of marine pollution caused by the transport of hazardous goods [13] or the life cycle impact assessment of environmental emissions from transport infrastructure [14].

The comparative analysis of the approaches presented above shows that none of the currently available methods enables the assessment of the environmental risks in the transport of the hazardous substances in the form of convergence of the areas concerned. In this case, there are, especially, the following three areas: The risk assessment of the serious accidents, the risk assessment in the transport of the hazardous substances, and the assessment of the environmental vulnerability. These three areas namely ensure the complex risk assessment at the transport of the hazardous substances in the context of the assessment of the potential impact on the environment. Thus, in the present study, a newly developed integrated approach to environmental risk assessment in the transport of hazardous substances (iTRANSRISK) is presented. The approach is based on the principle of modelling toxic and flammable substance leakage scenarios during transport in the context of environmental vulnerability indexing. 


\section{Materials and Methods}

The essence of this part of the article is the analysis of the materials and methods potentially suitable for the creation of the integral approach to the assessment of the environmental risks in the transport of hazardous substances (iTRANSRISK). According to the character of new proposed methods is the analysis of data focused into the three basic areas, which are (1) the accidents and their impact, (2) the methods of risks assessment of serious accidents, and (3) the approaches for the assessment of the environmental vulnerability. The most appropriate methods will then be used for the creating of the new integral approach.

\subsection{Accidents and Their Impacts}

In the past, numerous accidents involving the transport of hazardous substances have occurred around the world. Some of the most famous accidents include a road accident in 1976 in Houston, USA, involving an ammonia leak which killed 6 persons and injured another 178; a road accident in 1978 in San Carlos, Spain, involving a propylene explosion which killed 200 persons; a railway accident in 1979 in Mississauga, Canada, involving an LPG explosion and a chlorine leak which forced the evacuation of 200,000 persons; a railway accident in 1981 in Montanas, Mexico, involving a chlorine leak which killed 28 persons and injured another 1000; a railway accident in Lac-Mégantic, Canada in 2013, the oil explosion which killed 47 persons and forced the evacuation of 2000 persons [15].

The results of a study of 1932 accidents that occurred on roads and railways during the transport of hazardous substances show that the frequency of accidents is currently increasing. More than half of the accidents occurred on roads (63\%). The most frequent consequence of crashes was the spillage of substances $(78 \%)$, followed by fires $(28 \%)$, explosions (14\%) and gas clouds (6\%) [16].

The statistics of accidents involving the transport of hazardous substances are recorded in many countries. In the US, for example, data are available from the US Department of Transportation, Pipeline and Hazardous Materials Safety Administration. The risks of transporting hazardous substances in the US were evaluated in a study conducted by the Argonne National Laboratory [17]. The objective of this study was to quantitatively characterize the risks associated with the transportation of selected hazardous substances at the national level. Based on the results obtained for TIH (toxic by inhalation) substances, it was determined that chlorine and ammonia accounted for $70 \%$ to $80 \%$ of the total risks of fatalities related to accidents in the transportation of TIH substances (see Figure 1). A comparison of fatality risks based on miles and tons of substances transported indicated that the risks of transporting LPG significantly exceeded those for gasoline, TIH and explosives (see Figure 2).

\section{Total Fatality Risk}

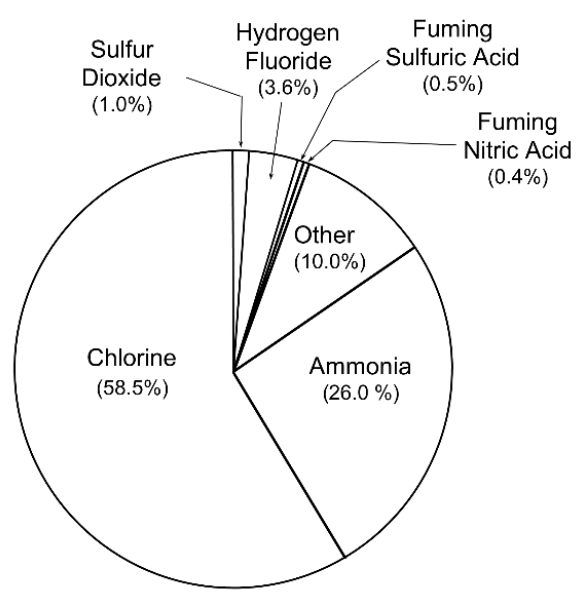

Figure 1. Breakdown of fatality risks associated the transportation of different TIH substances [17]. 


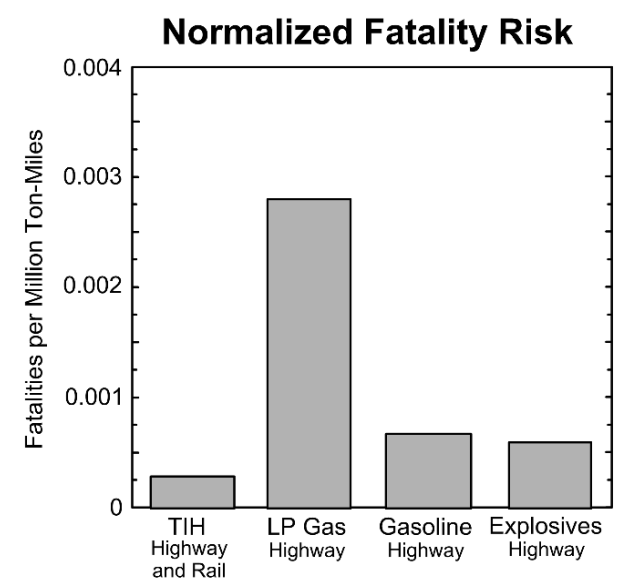

Figure 2. Normalized fatality risks in the transportation of different categories of hazardous substances [17].

Besides the possibility of fatalities and damage to property, an accident involving a hazardous substance may cause damage to the environment. Environmental consequences caused by such accidents may require several years to recover.

\subsection{Methods for Major Accident Risk Assessment}

The risk assessment of the transport of hazardous substances can be carried out using a number of different methods, which are mostly derived from the long-term experience in risk assessment of stationary sources of major accident hazards, mostly constituted by industrial facilities storing or processing hazardous substances. Methods for the quantitative risk assessment (QRA) of major accidents in fixed installations are presented and discussed in several handbooks. The following publications are among the most significant [18-22]. The methodologies more frequently used for the detailed assessment of major accident risks to the population are briefly outlined in the following.

An integrated risk analysis is allowed by the CPQRA methodology-Chemical Process Quantitative Risk Analysis [19]. This methodology was developed for the needs of the chemical industry based on experience from the nuclear, aircraft and electronics industries, although it may be applied also to other types of industry. CPQRA is a tool for the assessment and reduction of risk by means of specific methods and procedures.

Another acknowledged approach to the comprehensive risk assessment of major accidents, adopted in the Netherlands, is described in CPR 18E Guidelines for Quantitative Risk Assessment, known as the Purple Book [22]. This methodology consists of two parts, namely risk assessment for stationary installations and risk assessment for the transport of dangerous substances. In both parts of the risk assessment, the first step is always the selection of significant sources of risk or significant route segments. This approach aims to reduce the number of installations or transport units assessed in detail, thus simplifying the overall risk analysis and focusing attention on the most important risk sources. The Purple Book selection method has been developed to identify the facilities that provide the more important contribution to risk.

The ARAMIS methodology (Accidental Risk Assessment Methodology for Industries in the framework of the SEVESO II Directive) was developed within a project funded by the European Commission under the Fifth Framework Program (2002-2004). The ARAMIS project proposed a harmonized methodology for risk assessment. Its primary goal is to reduce uncertainties and variability in results and to include the assessment of risk management efficiency in the analysis. It is, thus, necessary to view ARAMIS as a global tool for carrying out effective risk identification and analysis with a whole series of preprepared and recommended steps [23].

An overview of the recommended methods available for risk analysis in the transport of hazardous substances is presented in Figure 3. 


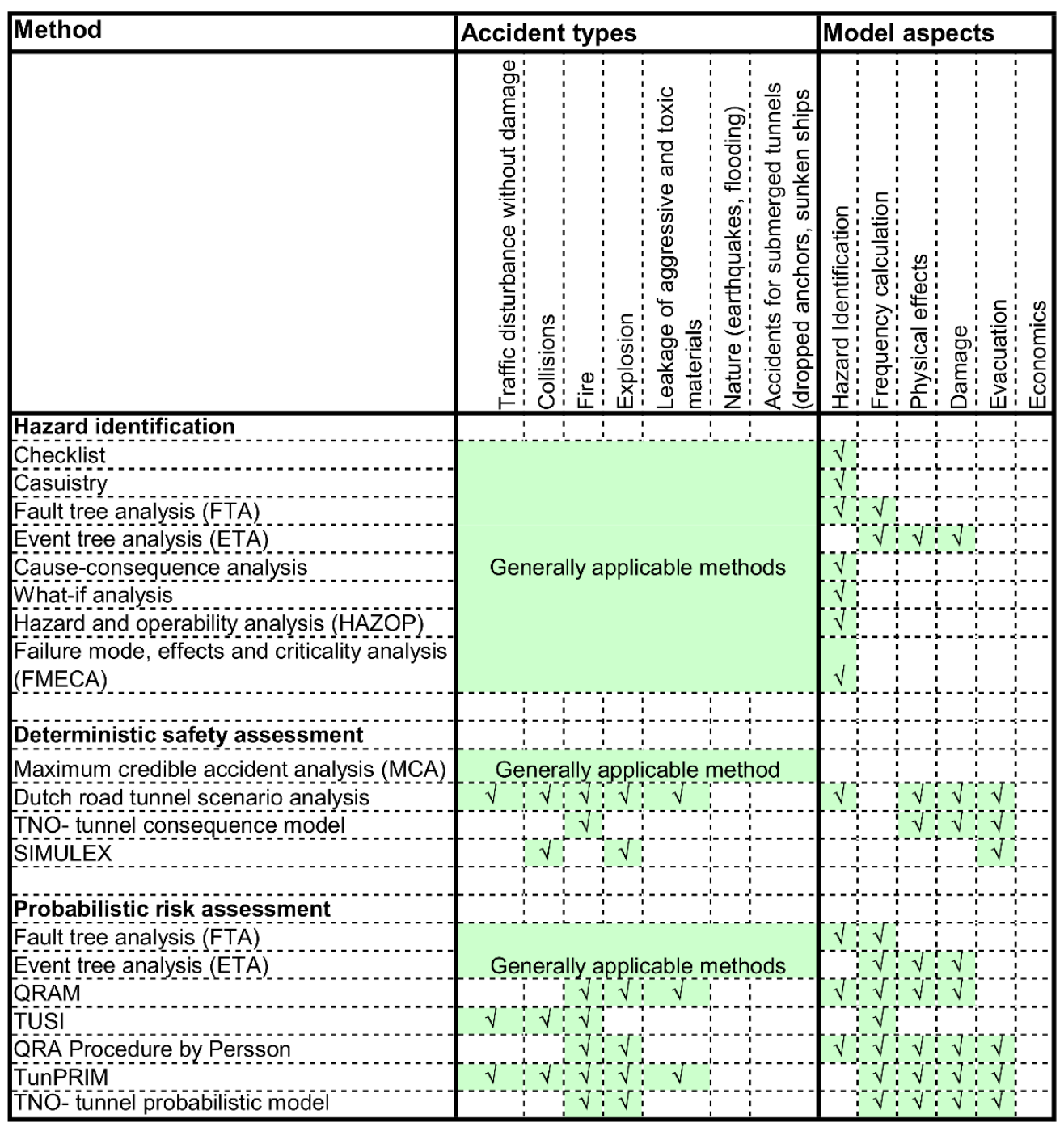

Figure 3. Overview of risk analysis methods for the transportation of hazardous substances [24].

Risk assessment methods for the transport of hazardous substances can range from those based on the principle of qualitative assessment (they estimate only the consequences of accidents) to complex methods having a quantitative nature (in addition to estimating the consequences of accidents, they also determine the probability of occurrence of the accidents). European legislation does not provide or recommend any methodology in this area. Nevertheless, among the most appropriate approaches the Failure Mode Effects and Criticality Analysis (FMECA), Quantitative Risk Assessment Model (QRAM), Chemical Transportation Risk Analysis (TRA) and Purple Book CPR 18E methodologies may be included.

The FMECA method is the extended version of FMEA method [25], which additionally includes into the process the criticality analysis. The original FMEA is the analytic method that aims to identify the causes of the failures and their consequences for the system or the enterprise. The FMEA identifies the simple faults that can significantly contribute to the accident, but they do not fit into the exhaustive list of faults. It is easy to use in process changes and modifications. It can be performed by one analyst, but it should be controlled by another one. The result is the qualitative systematic list of the devices, their failures, and consequences, with the possibility of the quantification. It also includes an estimate of the worst cases of the consequences. It is usually documented in the tabular form with the recommendations for the improving safety. 
The QRAM methodology [26] was designed to quantify the risks associated with the transport of dangerous goods in road tunnels. The main output of the QRAM methodology is to support the decision to allow or prohibit the operation of vehicles with dangerous goods in tunnels. The results of the simulation using the QRAM methodology are expressed in the form of social or expected risk. Using $\mathrm{F} / \mathrm{N}$ curves, the graph shows the social risk, where $\mathrm{F}$ is the cumulative probability of an accident (per $1000 \mathrm{~m}$ of route or tunnel length and per year) causing at least $\mathrm{N}$ fatalities. The resulting $\mathrm{F} / \mathrm{N}$ curve therefore shows the probability of exceeding a number $\mathrm{N}$ of fatalities.

The TRA methodology [16], published by the Center for Chemical Process Safety (CCPS) of the American Institute of Chemical Engineers (AIChE), specifies the types of failures and their frequencies for each type of transport (pipelines, rail, road, barges, ocean-going vessels), a selection of possible accident scenarios, case studies, etc. The methodology can also be used to identify potential risks. The TRA method results can aid decision-making in selecting the type of transport, the mode of transport if the combination of several modes is required, the appropriate transport alternatives, selecting the most suitable containers, developing contingency plans, transport risk management, etc. Proper application of TRA allows to support decision making within risk management on alternative modes of transport, appropriate routes, travel constraints (speed, weather, time of day), shipment size (total volume), etc.

For the purpose of quantitative risk assessment (QRA) of the transport of hazardous substances, the recommended risk assessment procedure for transport activities, which is presented in the second part of the Purple Book CPR 18E [22], can be applied. This procedure is based on an analysis of past accident reports. The applicability of this method for conducting risk studies is limited to the transport of hazardous substances on public routes using vehicles, trains, water transport and pipelines outside the boundaries of companies and transshipment sites.

\subsubsection{Major Accident Scenarios in the Transport of Hazardous Substances}

The publication A New QRA Model for Rail Transportation of Hazardous Goods [27] recommends the scenarios for the quantitative risk analysis on railways. For this purpose, it is appropriate to divide the hazardous substances into the liquid and gaseous substances. This division is shown in Figure 4. The kind and type of selected sub-stances correspond most to the transported substances, both by road and by rail [28].

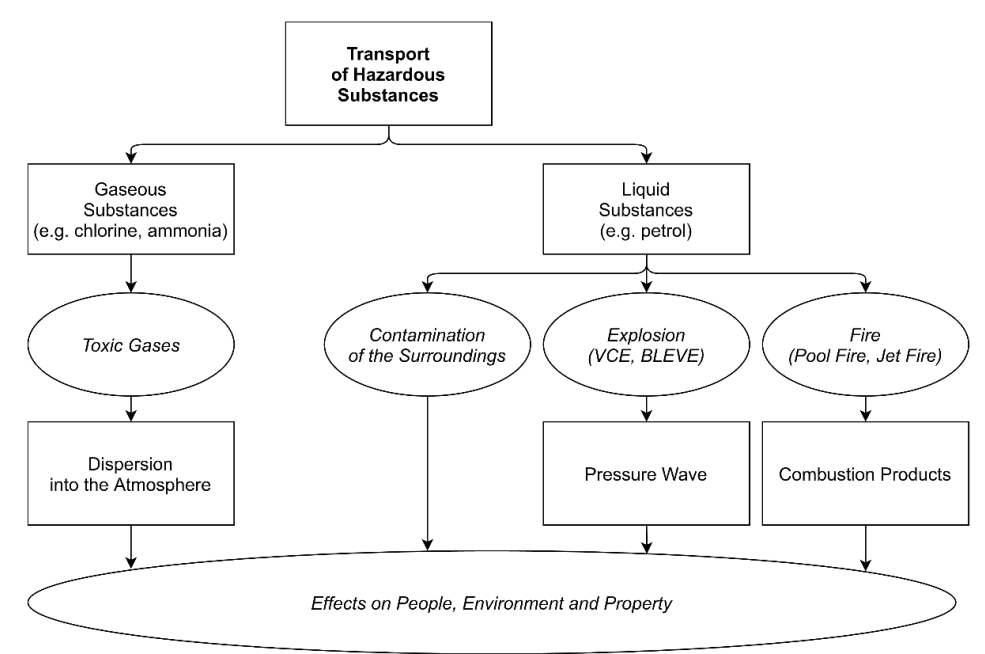

Figure 4. Overview of possible scenarios of severe incidents in the transport of hazardous substances (adapted from [28]). 


\subsubsection{Modelling of Hazardous Substance Release Scenarios during Transport}

The transport of hazardous substances poses a high potential danger, especially in densely populated areas of urban agglomerations, where the release of toxic substances into the air as a result of accidents can endanger the health or lives of large numbers of inhabitants. Similarly, leaks of gases and liquids can cause environmental pollution.

The consequences of accidents involving mobile sources of risk are currently only sporadically addressed, usually adopting simple mathematical models. These screening models, although inexpensive and widely used in practice, are mostly based on diffusion models and thus provide only an approximate estimate of the consequences of accidents. They do not take into account, for example, the detailed shape of terrain. These models are used to assess the consequences of accidental releases from stationary sources for the purpose of safety reports in industrial plants. However, in case of complex orography, the use of dynamic dispersion models is generally recommended. However, this approach, requiring a sophisticated numerical modelling, is currently not the standard in risk assessment procedures applied to major accident prevention.

Presently, some standard methodologies are used for major accident risk assessment and their implementation is supported by commercially available software tools. For example, the following software tools can be used to identify the zones where fatalities may occur:

- $\quad$ ALOHA 5.4.7.-freely available U.S. EPA software [29];

- EFFECTS 10-commercial software originally developed by TNO [30] and currently commercialized by Gexcon;

- TerEx 2.7.8.-commercial software from the Czech company T-SOFT [31].

ALOHA and EFFECTS are well-known software tools, mainly designed to allow consequence analysis of potential accident scenarios in preventive planning. TerEx is a tool designed primarily for emergency response teams in the event of an accident (operational modelling). These software tools can be used to obtain rough preliminary results. The hazard zones obtained are conservative and affected by uncertainty. The effect of obstacles (e.g., the presence of buildings) is not accounted. In most cases, the EFFECTS software provides less extended lethal zones, meaning that the ALOHA program is more conservative in terms of consequences and thus risk assessment. In a real situation, modelling inaccuracies caused by the prevailing weather conditions, wind direction and speed, uneven terrain, etc. need to be considered.

\subsubsection{Limits of Social Risk}

Currently, no international regulations apply to the acceptability of social risk. In single countries (e.g., UK and the Netherlands) criteria for the acceptability of social risk based on consequence/frequency curves (FN curves) are provided. As an example, in the $\mathrm{UK}$, societal risk is unacceptable if FN is higher than $10^{-1}$ events/year, while an "ALARPas low as reasonably possible" (sometimes also referred to as "as low as reasonably practicable") region is defined for FN between $10^{-4}$ and $10^{-1}$ events/year [32]. In the Netherlands, a specific criterion applies to the societal risk generated in the transportation of hazardous substances: societal risk is considered unacceptable if $\mathrm{FN}^{2}$ is higher than $10^{-1}$ events $/ \mathrm{km}$ year [33]. In several academic publications, the consequence/frequency curves (FN curves) are presented to summarize the societal risk deriving from scenarios generated by potential accidents, and are compared to recommended limits of acceptable risk. As an example, Tarada et al. [34] discuss the risk acceptability limits for rail transport in terms of protection objectives (see Figure 5).

For risk assessment purposes, the range of the ALARP region is also plotted in this diagram. If the risks falls in the ALARP area, it should be mitigated by additional measures where cost-effective. Specific studies may be issued to check the cost effectiveness of additional risk mitigation. 


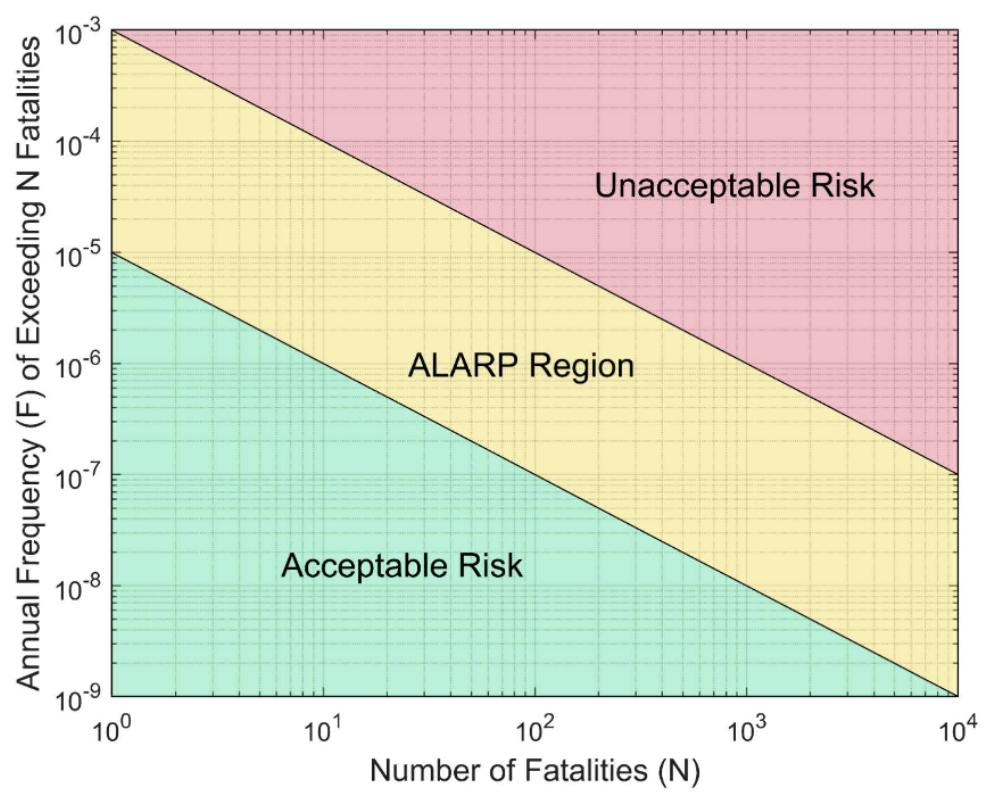

Figure 5. Societal risk acceptability plot for the transport of hazardous substances [7].

\subsection{Approaches to Environmental Vulnerability Assessment}

When assessing the environmental risks of transporting hazardous substances, besides the information about the nature of the hazardous substances and the possible loss of containment scenarios, it is also important to collect data concerning the vulnerability of the environment. Environmental vulnerability is conceptually different with respect to economic or social vulnerability, as the environment is a complex system with different levels of organization, energy and information flows [35]. In most cases, environmental indicators cannot be expressed by simple units and their thresholds vary widely. For such reasons, environmental vulnerability is often expressed through simplified indices that allow for easier comparisons in the context of risk assessment. The advantage of an index-based environmental vulnerability assessment is that it allows the assessor to work with a wide range of indicators, to establish risk levels and to define priorities.

Environmental vulnerability assessment has been the subject of a number of scientific publications. Weißhuhn et al. [36] recently presented a very extensive analysis of approaches to ecosystem vulnerability assessment, focusing on vulnerability assessment from different perspectives.

In the framework of the present study, publications focusing on index-based approaches to environmental vulnerability assessment need to receive particular attention. The REHRA (Rapid Environment and Health Risk Assessment) methodology, developed in 2000 by the World Health Organisation and the Italian Ministry for the Environment and Territory, is important in this context. The aim of the methodology is: (a) To identify the worst-case scenario in face of a severe accident at an industrial site causing a massive leakage of dangerous substances or energy into the environment (heat, radiation, blast waves); and (b) to support preventing, monitoring and managing risks and related foreseeable emergencies to protect health and the environment [37].

Another important method of environmental risk analysis is the Spanish ERI (Environmental Risk Index) methodology. This methodology is based on the identification, characterization and systematic assessment of all the relevant components and factors of a risk system. The risk system components considered include the risk source, the primary control systems, the transport systems and the vulnerable receptors. This semi-quantitative methodology allows the user to identify potential sources of major accident risks, to assess the vulnerability of each receptor and then to determine the severity of the effects of the hazardous substance on the potential receptor [38]. 
Environmental vulnerability assessment can also be performed using the EAI (Environment Accident Index) method. The EAI is a simple model which guides the identification and ranking of the type of assessment to be performed when dealing with different categories of hazardous chemicals. EAI consists of three sections: (a) Acute toxicity to organisms living in water (Tox), (b) stored or transported amount of the chemical (Am), and (c) factors controlling the spread of a chemical. The latter section, the so-called Spreading Part (consistency, solubility and properties of the surrounding environment), addresses the chemical and physical properties of the chemical, possibility of soil penetration and the depth and mobility of groundwater [39].

A further suitable methodology for assessing environmental vulnerability is the H\&V Index II (methodology for assessing the impact of accidents involving a dangerous substance on the environment). This is originally a Czech methodology, which is designed to assess the severity of an accident involving hazardous substances in the environment. The severity of the accident is scored by indices. Separate indices accounting for the hazard of the substance and the environmental vulnerability are determined. The resulting accident severity is a combination of the substance hazard index, the environmental vulnerability index and the amount of substance released into the environment during the accident. The output of the method is a risk matrix in which the acceptability of the risk is assessed [40].

Environmental vulnerability assessment can also be implemented through environmental resilience, which may be considered inverse to vulnerability [41]. The term resilience was first defined by Holling [42] in the context of the resistance and stabilization of ecological systems, and later of socio-ecological systems. Ecological resilience is the ability of an ecosystem to respond to disturbance, resist damage and recover rapidly. Such disturbances may include naturogenic events such as fires, floods and storms, but also anthropogenic activities such as deforestation, pesticide use or leaks of hazardous substances into soil and water. Large-scale disturbances may profoundly affect an ecosystem, forcing it to reach a threshold beyond which a different regime of processes and structures prevails [43]. When such thresholds are associated with a critical or bifurcation point, these regime shifts can also be referred to as critical transitions [44].

The assessment of environmental resilience has been the subject of several scientific publications over the last five years, presenting different approaches. The Need for Resilience in Environmental Impact Assessment is presented in Wenning et al. [45]. The authors agree that addressing resilience requires understanding the interconnectedness of environmental, social and economic issues affecting the sustainability of ecosystems and human communities. However, indicators and tools for measuring resilience remain in the early stages of understanding and development. Resilience, thus, presents a new challenge for environmental managers and decision makers working in environmental management contexts.

A similar view is also presented by Mahmoudi et al. [46], who support the combination of EIA methodology with synergistic concepts such as resilience, as this contributes to a more thorough and efficient EIA process. According to the authors, such a comprehensive approach is necessary for effective environmental impact assessment and management, and supports better decision-making. In their article, the authors presented a hybrid model of environmental assessment that combines EIA and resilience assessment. This approach extends the capability of EIA and allows for the management of uncertainties and unexpected outcomes associated with impacts on humans and the natural environment. Indeed, the application of resilience analysis in EIA can be a good tool for understanding systemic risks and then managing or monitoring these risks in the future.

A quantitative framework for assessing ecological resilience is presented by Baho et al. [47]. According to the authors, ecological resilience as an emergent ecosystem phenomenon can be decomposed into complementary attributes (scales, adaptive capacity, thresholds and alternative regimes) that encompass the complexity inherent in ecosystems. Quantifying these attributes simultaneously provides opportunities to move from assessing specific resilience within an ecosystem to a broader measure of its general resilience. This article provides a 
framework based on iterative testing and recalibration of hypotheses that assess additional attributes of ecological resilience. Angeler et al. [48] and Quinlan et al. [49] presented specific approaches to resilience assessment in ecosystems. Practical applications of environmental impact assessment combined with ecological resilience assessment are presented in several studies (e.g., see Moores et al. [50], Matthews et al. [51], Zhang et al. [52]).

It follows from the above that the impacts of the serious accidents on the environment can be assessed through either the resilience or the environmental vulnerability. From the results of analyzed studies, the authors came to the conclusion that the context of the solved problematics is more appropriate to pay attention to the environmental vulnerability, which is more detectable using the current methods. At the same time, however, it should be noted that none of the currently available approaches allows for an index-based assessment of environmental vulnerability to the impacts of major accidents involving the transport of hazardous substances. For this reason, the following section of this article focuses on the possibilities of an integrated approach to the assessment of environmental risks in the transport of hazardous substances. For this purpose, some of the methods presented above are used from the area of the risk assessment of the serious accidents and the environmental vulnerability assessment (see Section 3.1. Integrated approach to environmental risk assessment of accidents in the transport hazardous substances).

\section{Results}

The state of the art outlined above shows that none of the currently available methods allows the convergence of data from the assessment of the hazard potential of the substance being transported, with data concerning the assessment of the consequences and probability of a major accident, and data addressing environmental vulnerability assessment. On this basis, in the present study an integrated approach to environmental risk assessment in the transport of hazardous substances (iTRANSRISK) was developed. The approach is based on the principle of index-based assessment of toxic and flammable substance release scenarios during transport in the context of indexing environmental vulnerability.

\subsection{Integrated Approach to Environmental Risk Assessment of Accidents in the Transport of Hazardous Substances}

The key feature of the integrated approach proposed for the environmental risk assessment of accidents in the transport of hazardous substances is the integration of selected index methods that assess the individual components of environmental risk into a single overall index, as shown in Figure 6.

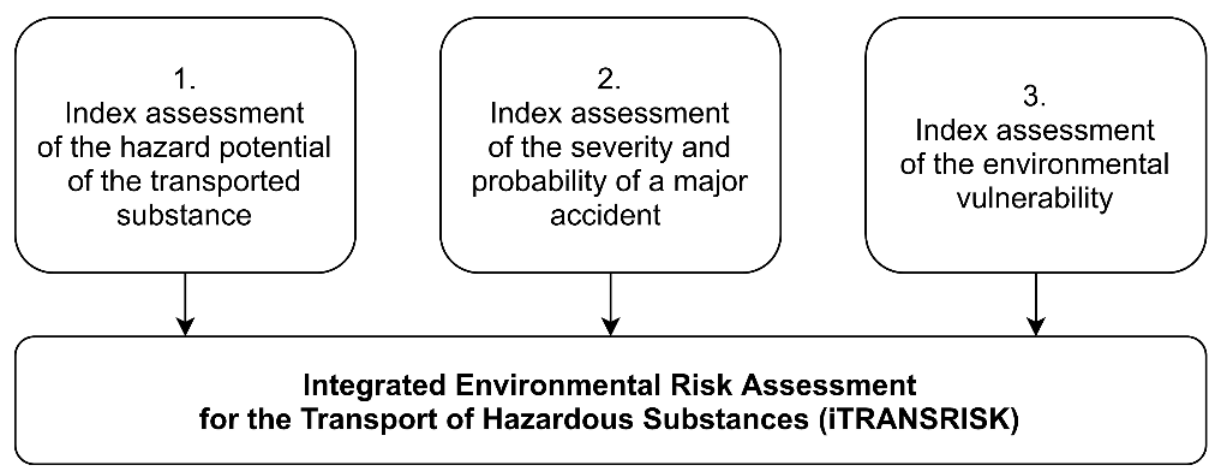

Figure 6. Concept of the integrated environmental risk assessment of accidents in the transport of hazardous substances.

In order to obtain a quantitative index to assess the potential consequences of a major accident, the Selective Method [22] was chosen. The method was selected due to the appropriate principles of basic risk source identification implemented. The main advantage of this method in the proposed integrated approach is to allow expressing the hazard level of a potential major accident through the Transported Hazard Potential Index $I_{H}$. 
A second important area of environmental risk assessment for accidents in the transport of hazardous substances is the assessment of the severity and probability of a major accident. For this purpose, the FMEA method [25] was selected to evaluate the causes and consequences of a potential failure. The advantage of this method in the proposed integrated approach is possibility to express of the probability of a major accident through the Major Accident Severity and Probability Index $I_{P}$.

For the purpose of the index-based assessment of environmental vulnerability, the H\&V Index II method [40] was selected, as it allows the assessment of the severity of an accident involving the release of a hazardous substance in the environment. The aim of this method in the proposed integrated approach is to provide a quantitative assessment of environmental vulnerability through the Environmental Vulnerability Index $I_{V}$.

The integration of the above methods into a single procedure was obtained by the integration of the Transport Hazard Potential Index $I_{H}$ and the Environmental Vulnerability Index $I_{V}$ into the FMEA method, which provides the Major Accident Severity and Probability Index $I_{P}$. Thus, the Environmental Risk Index $I_{R}$ is obtained, which specifies the level of environmental risk in the transport of the selected hazardous substance.

\subsection{Environmental Risk Assessment Procedure for Accidents in the Transport of Hazardous Substances}

Based on the definition of the concept of an integrated approach to environmental risk assessment in the transport of hazardous substances, it is possible to proceed to the definition of a specific procedure. The essence of this procedure is to establish a clear user manual for the assessment of environmental risks in the transport of hazardous substances. It is a multi-step procedure based on the integration of the Selective Method [22] and the H\&V Index II method [40] into the FMEA method [25]. The algorithm of this integrated approach is presented in Figure 7.

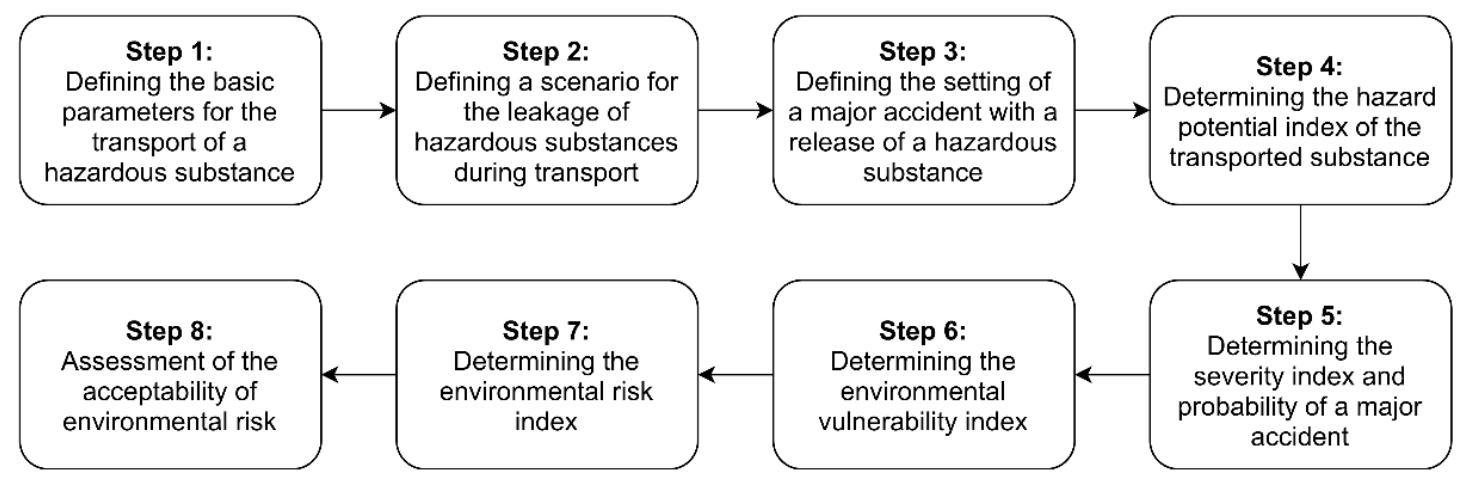

Figure 7. Flow chart for the integrated environmental risk assessment of accidents in the transport of hazardous substances.

Based on the definition of the concept of the integrated approach to environmental risk assessment for accidents in the transport of hazardous substances, it is possible to proceed to the definition of a specific procedure. The aim of this procedure is to establish and provide a clear user manual for the assessment of environmental risks due to accidents in the transport of hazardous substances. The resulting overall procedure is a multistep method based on the integration of the Selective Method [22] and the H\&V Index II method [40] into the FMEA method [25]. The flow chart of the overall procedure is presented in Figure 7.

Step 1: Defining the Basic Parameters for the Transport of a Hazardous Substance

In the first step of the procedure for the integrated environmental risk assessment for accidents in the transport of hazardous substances, it is necessary to define the basic parameters for the transport of a hazardous substance. The essence of this step is to define the basic information necessary to assess the consequences of a major accident. Specifically, 
this includes an assessment of the type and hazardous characteristics of the substance being transported and the safety measures undertaken.

Step 2: Defining a Scenario for the Leakage of Hazardous Substances During Transport

The next step of the algorithm is to define the scenario of a hazardous substance leak during transport. The aim of this step is to define the manifestation of the failure, the cause of leakage of the hazardous substance and the consequences of a major accident (i.e., to determine the quantity of the hazardous substance released). Some specific methods can be used for this purpose, such as fault tree analysis - FTA [53] or event tree analysis -ETA [54].

Step 3: Defining the Setting of a Major Accident with a Release of a Hazardous Substance

The third step of the algorithm is to define the setting of a major accident with the leakage of a hazardous substance. The aim of this step is to define the vulnerability of the different environmental compartments in the location assumed for the major accident. Specifically, this involves identifying the presence of surface water, groundwater, soil and biotic components of the environment.

Step 4: Determining the Hazard Potential Index of the Transported Substance

The fourth step is to determine the hazard potential index of the transported substance $I_{H}$. As already mentioned in the concept of the integral approach (see Section 3.1), for this purpose is it appropriate to use the Selective Method [22], specifically Equation (1):

$$
I_{H}=\frac{Q \times O 1 \times O 2}{G}
$$

where $I_{H}=$ the hazard potential index of the transported substance (1-5); $Q=$ the quantity of the transported hazardous substance $(\mathrm{kg}) ; \mathrm{O} 1=$ the factor of the hazardous substance's state (0.1-10); $O 2$ = the factor of process conditions in the transport unit (1-10); $G=$ the limit quantity of the hazardous substance $(\mathrm{kg})$.

Equation (1) is designed for the evaluation of toxic and flammable substances, where for the purposes of calculating flammable substances the comparative limit quantity is set at $10,000 \mathrm{~kg}$ (this value does not limit the amount of the substance under the assessment). The calculation for toxic substances is transferred from the $\mathrm{LC}_{50}$ concentration according to the principle of The Selective Method [22]. The higher the calculated index values, the greater the accident potential of the transported substance. The quantitative expression of the transported substance hazard potential index is based on the Selective Method [22] and has been converted to a qualitative expression on a scale of 1 to 5 for the purpose of the iTRANSRISK method (see Table 1). These reference values have been established based on the long-term practical experience using the Selective Method in many industrial enterprises when processing the risk analyses of the serious accidents.

Table 1. Reference values for calculating the hazard potential index of a transported substance.

\begin{tabular}{cc}
\hline Value from Equation (1) & $\begin{array}{c}\text { Reference Value to be Used } \boldsymbol{I}_{\boldsymbol{H}} \text { in } \\
\text { iTRANSRISK }\end{array}$ \\
\hline $0.1-10$ & 1 \\
$11-50$ & 2 \\
$51-100$ & 3 \\
$101-150$ & 4 \\
151 and more & 5 \\
\hline
\end{tabular}

An example of how to determine the hazard potential index of a transported substance is presented in Table 2. 
Table 2. Examples of determination of the hazard potential index of the transported substance.

\begin{tabular}{|c|c|c|c|c|c|c|}
\hline Transport Unit & $Q$ & 01 & $\mathrm{O} 2$ & $G$ & $\begin{array}{l}\text { Value from } \\
\text { Equation (1) }\end{array}$ & $I_{H}$ \\
\hline Propane cylinder (50 kg) & 50 & 10 & 10 & 10,000 & 0.5 & 1 \\
\hline Propane tanker $(18 \mathrm{t})$ & 18,000 & 10 & 10 & 10,000 & 180 & 5 \\
\hline Chlorine barrel (500 kg) & 500 & 10 & 10 & 300 & 166 & 5 \\
\hline
\end{tabular}

Step 5: Determining the Severity Index and Probability of a Major Accident

The fifth step of the algorithm is to determine the probability index of a severe accident $I_{P}$. As already mentioned in the concept of the integral approach (see Section 3.1), for this purpose is it appropriate to use the FMEA method [25], specifically Equation (2):

$$
I_{P}=\frac{S+O+D}{3}
$$

where $I_{P}=$ the probability index of a severe accident $(1-5) ; S=$ the severity of the accident during the transport of a hazardous substance $(1-5) ; O=$ the probability of occurrence of a problem (1-5); $D=$ the probability of detection (1-5).

The values of the different factors needed for the calculation of the Severe Accident Probability Index by Equation (2) are obtained from Table 3.

Table 3. Criteria for the selection of the values needed to calculate the Severe Accident Probability Index [25].

\begin{tabular}{cccccc}
\hline Severity & \multicolumn{2}{c}{ Occurrence } & \multicolumn{2}{c}{ Detection } \\
\hline barely perceptible & 1 & unlikely & 1 & high & 1 \\
irrelevant & 2 & very low & 2 & moderate & 2 \\
moderately significant & 3 & low & 3 & low & 3 \\
severe & 4 & moderate & 4 & very low & 4 \\
extremely severe & 5 & high & 5 & unlikely & 5 \\
\hline
\end{tabular}

An example of how the Severe Accident Probability Index is determined is presented in Table 4.

Table 4. Examples of calculation of the Severe Accident Probability Index of a major accident.

\begin{tabular}{|c|c|c|c|c|c|c|c|}
\hline Scenario & $\begin{array}{l}\text { Manifestation } \\
\text { of Malfunction }\end{array}$ & $\begin{array}{l}\text { Consequence of } \\
\text { Malfunction }\end{array}$ & $\begin{array}{c}\text { Cause of } \\
\text { Malfunction }\end{array}$ & $S$ & $O$ & $D$ & $I_{P}$ \\
\hline $\begin{array}{l}\text { Explosion after } \\
\text { propane leak from a } \\
\text { cylinder }(50 \mathrm{~kg})\end{array}$ & $\begin{array}{l}\text { Pressure wave } \\
\text { propagation after } \\
\text { an explosion }\end{array}$ & $\begin{array}{l}\text { Fatal injuries to } \\
\text { persons, evacuation, } \\
\text { interruption of traffic }\end{array}$ & $\begin{array}{l}\text { Traffic accident, } \\
\text { human error, } \\
\text { technical failure }\end{array}$ & 3 & 2 & 3 & 2.6 \\
\hline $\begin{array}{l}\text { Explosion after } \\
\text { propane leak from a } \\
\text { tanker }(18 \mathrm{t})\end{array}$ & $\begin{array}{l}\text { Pressure wave } \\
\text { propagation after } \\
\text { an explosion }\end{array}$ & $\begin{array}{l}\text { Fatal injuries to } \\
\text { persons, evacuation, } \\
\text { interruption of } \\
\text { service (long-term) }\end{array}$ & $\begin{array}{l}\text { Traffic accident, } \\
\text { human error, } \\
\text { technical failure }\end{array}$ & 5 & 2 & 3 & 3.3 \\
\hline $\begin{array}{l}\text { Toxic gas cloud after } \\
\text { chlorine leak from a } \\
\text { barrel }(500 \mathrm{~kg})\end{array}$ & $\begin{array}{l}\text { Spread of a toxic } \\
\text { gas cloud }\end{array}$ & $\begin{array}{l}\text { Fatal injuries to } \\
\text { persons, evacuation, } \\
\text { interruption of traffic }\end{array}$ & $\begin{array}{l}\text { Traffic accident, } \\
\text { human error, } \\
\text { technical failure }\end{array}$ & 4 & 2 & 3 & 3.0 \\
\hline
\end{tabular}

Step 6: Determining the Environmental Vulnerability Index

The aim of the sixth step of the algorithm is to determine the environmental vulnerability index $I_{V}$. As already mentioned in the concept of the integral approach (see Section 3.1) for this purpose is it appropriate to use the H\&V Index II method [40], specifically Equation (3):

$$
I_{V}=\frac{I_{S W}+I_{U W}+I_{S}+I_{B}}{4}
$$


where $I_{V}=$ the index of environmental vulnerability (1-5); $I_{S W}=$ the index of surface water vulnerability (1-5); $I_{U W}=$ the index of groundwater vulnerability $(1-5) ; I_{S}=$ the index of soil vulnerability $(1-5) ; I_{B}=$ the index of biotic vulnerability (1-5).

Table 5 provides a guidance to the selection of the individual values of the indexes needed to calculate the environmental vulnerability index by the expression provided in Equation (3).

Table 5. Criteria for the selection of the values of the indexes needed for the application of Equation (3) to the calculation of the overall environmental vulnerability index.

\begin{tabular}{|c|c|c|c|c|c|c|c|}
\hline Surface Water $I_{S W}$ & & Groundwater $I_{U W}$ & & Soil Environment $I_{S}$ & & Biotic Components $I_{B}$ & \\
\hline $\begin{array}{c}\text { Sewage system leading } \\
\text { to WWTP, } \\
\text { sedimentation field, } \\
\text { tailings pond }\end{array}$ & 1 & $\begin{array}{l}\text { Territory without } \\
\text { sanitary protection } \\
\text { zone }\end{array}$ & 1 & $\begin{array}{l}\text { Heavy resistant soils (black } \\
\text { earth soils, rendzina) }\end{array}$ & 1 & $\begin{array}{c}\text { Cultivated agricultural } \\
\text { land }\end{array}$ & 1 \\
\hline Other surface waters & 2 & $\begin{array}{l}\text { Protected area of } \\
\text { natural water } \\
\text { accumulation }\end{array}$ & 2 & $\begin{array}{l}\text { Medium and heavy soils with } \\
\text { low susceptibility (black } \\
\text { earth, brown earth, alluvial } \\
\text { and floodplain soils) }\end{array}$ & 2 & $\begin{array}{l}\text { Meadows, pastures, } \\
\text { gardens and parks }\end{array}$ & 2 \\
\hline $\begin{array}{c}\text { Rainwater drainage, } \\
\text { ditches, drainage, } \\
\text { ponds and flooded } \\
\text { mining pits }\end{array}$ & 3 & $\begin{array}{l}\text { Hygienic protection } \\
\text { zone level } 2 \text { (external) }\end{array}$ & 3 & $\begin{array}{l}\text { Medium and heavy } \\
\text { susceptible soils (illimerized } \\
\text { and silty soils) }\end{array}$ & 3 & $\begin{array}{l}\text { Forests, orchards, } \\
\text { vineyards, hops }\end{array}$ & 3 \\
\hline $\begin{array}{l}\text { Border areas, peatland, } \\
\text { wetlands }\end{array}$ & 4 & $\begin{array}{l}\text { Hygienic protection } \\
\text { zone level } 2 \text { (internal) }\end{array}$ & 4 & $\begin{array}{l}\text { Light and medium highly } \\
\text { susceptible soils (strongly } \\
\text { acidic brown soils, shallow } \\
\text { soils and soils in very } \\
\text { sloping positions) }\end{array}$ & 4 & $\begin{array}{l}\text { Territorial system of } \\
\text { ecological stability of } \\
\text { regional and local } \\
\text { importance, natural and } \\
\text { priority habitats }\end{array}$ & 4 \\
\hline Waterworks & 5 & $\begin{array}{l}\text { Hygienic protection } \\
\text { zone level } 1\end{array}$ & 5 & $\begin{array}{l}\text { Light non-resistant soils (soils } \\
\text { on sands and gravels) }\end{array}$ & 5 & $\begin{array}{l}\text { Specially protected area, } \\
\text { territorial system of } \\
\text { ecological stability of } \\
\text { national importance }\end{array}$ & 5 \\
\hline
\end{tabular}

An example of how the environmental vulnerability index is determined is presented in Table 6.

Table 6. Example of calculation of the environmental vulnerability index.

\begin{tabular}{cccccc}
\hline Territory Description & Level of Protection & $I_{S W}$ & $I_{U W}$ & $I_{S}$ & $I_{B}$ \\
\hline $\begin{array}{c}\text { No surface water } \\
\text { No groundwater } \\
\begin{array}{c}\text { Moderately susceptible soil } \\
\text { Wooded area }\end{array}\end{array}$ & No degree of protection & 1 & 1 & 3 & 3 \\
\hline
\end{tabular}

Step 7: Determining the Environmental Risk Index

The seventh step requires determination of the Environmental Risk Index IR, which is calculated according to Equation (4):

$$
I_{R}=I_{H} \times I_{P} \times I_{V}
$$

where $I_{R}=$ the Environmental Risk Index (1-125); $I_{H}=$ the index of hazard potential of the substance being transported (1-5); $I_{P}=$ the index of probability of a major accident (1-5); $I_{V}=$ the index of environmental vulnerability (1-5).

An example of how to calculate the Environmental Risk Index IR is presented in Table 7. The example addresses an explosion scenario following a propane tanker leak $(18 \mathrm{t})$ in a forested area with moderately susceptible soils and no surface or groundwater. 
Table 7. Example of calculation of the overall Environmental Risk Index for a leak from an $18 \mathrm{t}$ propane tanker.

\begin{tabular}{ccc}
\hline Components & Indexes & Sub-Indexes \\
\hline Transported Hazard Potential Index & $I_{H}=5.0$ & $Q=18,000 ; O 1=10 ; O 2=10 ; G=10,000 ;$ \\
Value from Equation $(1)=180$ \\
Major Accident Severity and Probability Index & $I_{P}=3.3$ & $S=5 ; O=2 ; D=3$ \\
Environmental Vulnerability Index & $I_{V}=2.0$ & $I_{S W}=1 ; I_{U W}=1 ; I_{S}=3 ; I_{B}=3$ \\
Environmental Risk Index & $I_{R}=33$ & $I_{H}=5.0 ; I_{P}=3.3 ; I_{V}=2.0$ \\
\hline
\end{tabular}

Step 8: Assessment of the Acceptability of Environmental Risk

The final step in the proposed algorithm for an integrated approach to environmental risk assessment for accidents in the transport of hazardous substances consists in the assessment of the acceptability of the environmental risk, which should be carried out according to benchmark values provided in Table 8 .

Table 8. Benchmark values for assessing the acceptability of environmental risk.

\begin{tabular}{cc}
\hline $\boldsymbol{I}_{\boldsymbol{R}}$ & Acceptability of Environmental Risk \\
\hline$\langle 1.0 ; 25.8\rangle$ & Negligible risk \\
$(25.8 ; 50.6\rangle$ & Acceptable risk \\
$(50.6 ; 75.4\rangle$ & Low risk \\
$(75.4 ; 100.2\rangle$ & High risk \\
$(100.2 ; 125.0\rangle$ & Critical risk \\
\hline
\end{tabular}

The distribution of benchmark values for the environmental risk acceptability assessment of $I_{R}$ in Table 8 is based on the FMEA method [52], which works with multiple variables in determining the level of risk and relies on the variation of their extreme values in assessing states. In a similar manner, individual environmental risk levels were determined to account for variations in extreme values (i.e., 1 and 125):

- $1 ; 1 ; 1 ; 1 ; 1 \rightarrow \varnothing 1.0$

- $1 ; 1 ; 1 ; 1 ; 125 \rightarrow \varnothing 25.8$

- $1 ; 1 ; 1 ; 125 ; 125 \rightarrow \varnothing 50.6$

- $1 ; 1 ; 125 ; 125 ; 125 \rightarrow \varnothing 75.4$

- $1 ; 125 ; 125 ; 125 ; 125 \rightarrow \varnothing 100.2$

- $125 ; 125 ; 125 ; 125 ; 125 \rightarrow \varnothing 125.0$

On the basis of the classification of the reference values presented above, it is possible to proceed to assessing the acceptability of environmental risk for the model scenario of an explosion after a propane tank leak (18 $\mathrm{t}$ ) in a forested area with moderately susceptible soil without surface or groundwater. In this case, the value of the overall Environmental Risk Index $I_{R}$ reported in Table 7 equals 33, indicating an acceptable risk. A reduction in the risk value could be achieved reducing the amount of substance transported or choosing a route through areas having a lower environmental vulnerability.

\subsection{Discussion}

It is important to remark on the benefits of the newly developed integrated approach to environmental risk assessment for accidents in the transport of hazardous substances (iTRANSRISK). These clearly emerge from Table 9, where the results of a multi-criteria comparison of currently available environmental risk assessment methods are reported. As shown in the table, for the purpose of comparing the available methods with the proposed iTRANSRISK methodology, selected criteria such as the suitability of the method for assessing mobile sources of risk, the demand on time to develop the method, the ease of interpretation of the results and the limitations in the quantity of hazardous substance were used. The selected criteria reflect the authors' requirements for the simplicity, the time modesty, and the wide applicability of the proposed method. 
Table 9. Comparison of iTRANSRISK to other environmental risk assessment methods available in the literature and suitable for the assessment of environmental risk generated by accidents in the transport of hazardous substances.

\begin{tabular}{ccccc}
\hline & \multicolumn{3}{c}{ Comparison Criteria } \\
\cline { 2 - 5 } $\begin{array}{c}\text { Environmental Risk } \\
\text { Assessment Methods }\end{array}$ & $\begin{array}{c}\text { Suitability of the } \\
\text { method for assessing } \\
\text { mobile sources of risk }\end{array}$ & $\begin{array}{c}\text { Low demand on } \\
\text { time for method } \\
\text { development }\end{array}$ & $\begin{array}{c}\text { Ease of interpretation of } \\
\text { results (index methods) }\end{array}$ & $\begin{array}{c}\text { Not including restrictions } \\
\text { on the quantity of } \\
\text { hazardous substance }\end{array}$ \\
\hline iTRANSRISK (present & YES & YES & YES & YES \\
study) & YES & NO & YES & YES \\
TRAM [25] & YES & NO & YES & NO \\
Purple Book [22] & YES & NO & NO & YES \\
ARAMIS [23] & NO & NO & NO \\
\hline
\end{tabular}

The above comparison shows that the newly developed iTRANSRISK method is the most suitable for rapid assessment of environmental risks due to accidents in the transport of hazardous substances. Other methods are much more demanding with respect to expertise, time and calculation resources required, and in several cases do not allow an easy interpretation of the results. At the same time, it should be noted that for this reason, the iTRANSRISK method is only suitable for a screening risk assessment. A more detailed assessment needs to be carried out with other literature methodologies available to the purpose, as discussed above, or using the more advanced statistical and calculation methods, such as data and/or dynamic models $[55,56]$.

\section{Conclusions}

The article presents a newly created integral approach for the risk assessment in the transport of the hazardous substances (iTRANSRISK). This approach is based on the principle of index-based assessment of toxic and flammable substance release scenarios during transport in the context of indexing environmental vulnerability. The aim of this approach is the conversion and the integration of the data from the assessment of the risk potential of the transported substance, of the consequences and probability of a major accident, and of environmental vulnerability assessment into a single overall index. The basis of this approach is a procedure, specifically developed, allowing the screening of environmental risk due to accidents in the transport of hazardous substances. The algorithm developed consists of eight steps and also allows the assessment of the acceptability of the environmental risk.

The integrated approach developed is designed to meet the needs of both hazardous substance transporters and public administration, which can apply the simple screening method developed in the present study to pre-analyze critical hazardous substance transport sites with high environmental vulnerability. The proposed approach is determined for the screening risk assessment at the beginning of the process of the planning a suitable transport routes and the results are for information only. In case of identification of an increased risk, it is appropriate to perform the complex assessment using some more difficult and time-consuming methods.

At present, research addressing the reduction of environmental risk due to major accidents is mainly focused on stationary sources of hazards within industrial facilities. However, the gradual increase in the amount of transported substances will require to also devote attention to accidents in the transport of hazardous substances, which, especially in vulnerable locations, may cause irreversible environmental losses. For this reason, followup research will focus mainly on the further development of index parameters and on their use in the integrated assessment of environmental risks caused by accidents in the transport of hazardous substances. 
Author Contributions: Conceptualization, A.B., D.R. and V.C.; methodology, A.B., D.R., V.C., P.F., J.V. and F.P.; validation, A.B., D.R., V.C., P.F., J.V. and F.P.; formal analysis, P.F., J.V. and F.P.; investigation, A.B., D.R. and V.C.; resources, A.B., D.R. and V.C.; data curation, P.F., J.V. and F.P.; writing-original draft preparation, A.B., D.R., V.C., P.F., J.V. and F.P.; writing-review and editing, A.B., D.R., V.C., P.F., J.V. and F.P.; visualization, D.R.; supervision, A.B.; project administration, A.B.; funding acquisition, A.B. All authors have read and agreed to the published version of the manuscript.

Funding: This research was funded by the Ministry of the Interior of the Czech Republic, grant number VJ01030011.

Institutional Review Board Statement: Not applicable.

Informed Consent Statement: Not applicable.

Conflicts of Interest: The authors declare no conflict of interest.

\section{References}

1. Council Directive 2012/18/EU of 4 July 2012 on the Control of Major-Accident Hazards Involving Dangerous Substances; Office for Official Publications of the European Communities: Luxembourg, 2012.

2. ISO 31000. Risk Management-Guidelines; International Organization for Standardization: Geneva, Switzerland, 2018.

3. Zhang, J.; Zhao, L. Risk Analysis of Dangerous Chemicals Transportation. Syst. Eng.-Theory Pract. 2007, 27, 117-122. [CrossRef]

4. Milazzo, M.F.; Lisi, R.; Maschio, G.; Antonioni, G.; Spadoni, G. A Study of Land Transport of Dangerous Substances in Eastern Sicily. J. Loss Prev. Process. Ind. 2010, 23, 393-403. [CrossRef]

5. Saat, M.R.; Werth, C.J.; Schaeffer, D.; Yoon, H.; Barkan, C.P.L. Environmental Risk Analysis of Hazardous Material Rail Transportation. J. Hazard. Mater. 2014, 264, 560-569. [CrossRef] [PubMed]

6. Zelenko, Y.; Dzhus, O.; Dzhus, V.; Yanchenko, D. Methodology of Risk Assessment and Forms of Environmental Safety Management for the Transport of Dangerous Goods by Railway Transport. In Proceedings of the 2nd International Scientific and Practical Conference "Energy-Optimal Technologies, Logistic and Safety on Transport" (EOT-2019), Lviv, Ukraine, 19-20 September 2019; Volume 294. [CrossRef]

7. Ehrhart, B.D.; Brooks, D.; Muna, A.B.; LaFleur, C. Evaluation of Risk Acceptance Criteria for Transporting Hazardous Materials; Sandia National Laboratories: Albuquerque, NM, USA, 2020.

8. Saska, T. Risk Quantification for Environment Elements along the Traffic Route. Trans. VSB-Tech. Univ. Ostrav. Saf. Eng. Ser. 2012, 7, 37-43. [CrossRef]

9. Macias, A.; Gadziński, J. Assessment of Road Transport Environmental Impact as Illustrated by a Metropolitan Area. Pol. J. Environ. Stud. 2013, 22, 1749-1758.

10. Häkkinen, J.; Malk, V.; Posti, A.; Penttinen, O.P.; Mäkelä, R.; Kiiski, A. Environmental Risk Assessment of the Most Commonly Transported Chemicals: Case Study of Finnish Coastal Areas. WMU J. Marit. Aff. 2013, 12, 147-160. [CrossRef]

11. Conca, A.; Ridella, C.; Sapori, E. A Risk Assessment for Road Transportation of Dangerous Goods: A Routing Solution. Transp. Res. Procedia 2016, 14, 2890-2899. [CrossRef]

12. Dvorak, Z.; Rehak, D.; David, A.; Cekerevac, Z. Qualitative Approach to Environmental Risk Assessment in Transport. Int. J. Environ. Res. Public Health 2020, 17, 5494. [CrossRef]

13. Popek, M. Factors Influencing on the Environment during Hazardous Goods Transportation by the Sea. In Proceedings of the IOP Conference Series: Earth and Environmental Science, Krakow, Poland, 14-17 November 2017; Volume 214. [CrossRef]

14. Li, H.; Deng, Q.; Zhang, J.; Olubunmi Olanipekun, A.; Lyu, S. Environmental Impact Assessment of Transportation Infrastructure in the Life Cycle: Case Study of a Fast Track Transportation Project in China. Energies 2019, 12, 1015. [CrossRef]

15. Oggero, A.; Darbra, R.M.; Munoz, M.; Planas, E.; Casal, J. A Survey of Accidents Occurring During the Transport of Hazardous Substances by Road and Rail. J. Hazard. Mater. 2006, 133, 1-7. [CrossRef]

16. Center for Chemical Process Safety. Guidelines for Chemical Transportation Risk Analysis; Wiley-AIChE: New York, NY, USA, 1995.

17. Brown, D.F.; Dunn, W.E.; Policastro, A. A National Risk Assessment for Selected Hazardous Materials Transportation; Argonne National Laboratory: Lemont, IL, USA, 2001. [CrossRef]

18. Mannan, S. Lees' Loss Prevention in the Process Industries: Hazard Identification, Assessment and Control, 4th ed.; ButterworthHeinemann: Oxford, UK, 2012. [CrossRef]

19. Center for Chemical Process Safety. Guidelines for Chemical Process Quantitative Risk Analysis (CPQRA), 2nd ed.; Wiley-AIChE: New York, NY, USA, 1999.

20. Center for Chemical Process Safety. Layer of Protection Analysis: Simplified Process Risk Assessment; Wiley-AIChE: New York, NY, USA, 2001.

21. Van den Bosch, C.J.H.; Weterings, R.A.P.M. Methods for the Calculation of Physical Effects: Due to Releases of Hazardous Materials (Liquids and Gases) "Yellow Book", 3rd ed.; Sdu Uitgevers: The Hague, The Netherlands, 2005.

22. Uijt de Haag, P.A.M.; Ale, B.J.M. Guidelines for Quantitative Risk Assessment "Purple Book", 3rd ed.; Sdu Uitgevers: The Hague, The Netherlands, 2005. 
23. Delvosalle, C.; Fievez, C.; Pipart, A.; Debray, B. ARAMIS project: A comprehensive methodology for the identification of reference accident scenarios in process industries. J. Hazard. Mater. 2006, 130, 200-219. [CrossRef] [PubMed]

24. Molag, M.; Trijssenaar-Buhre, I.J.M. Risk Assessment Guidelines for Tunnels. In Proceedings of the 2nd International Symposium Safe \& Reliable Tunnels: Innovative European Achievements, Lausanne, Switzerland, 30-31 May 2006.

25. IEC 60812. Failure Modes and Effects Analysis (FMEA and FMECA); International Electrotechnical Commission: Geneva, Switzerland, 2018.

26. INERIS. Transport of Dangerous Goods through Road Tunnels, Quantitative Risk Assessment Model (v. 3.60 and v. 3.61). User's Guide and Reference Manual; French National Institute for Industrial Environment and Risks: Verneuil-en-Halatte, France, 2005.

27. Bouissou, C.; Ruffin, E.; Defert, R.; Prats, F.; Dannin, E. A new QRA Model for Rail Transportation of Hazardous Goods. In Proceedings of the 11th International Symposium on Loss Prevention and Safety Promotion in the Process Industry, Prague, Czech Republic, 31 May-3 June 2004; pp. 4283-4289.

28. Pribyl, P.; Janota, A.; Spalek, J. Risk Analysis and Management in Transport; BEN-Technická Literatura: Prague, Czech Republic, 2008. (In Czech)

29. ALOHA Software. Agency. Available online: https://www.epa.gov/cameo/aloha-software (accessed on 16 July 2021).

30. EFFECTS Advanced, Easy-To-Use Consequence Analysis. Available online: https://www.tno.nl/media/10741/effects-brochure. pdf (accessed on 19 July 2021).

31. TEREX-TERrorism EXpert. Available online: https://www.tsoft.cz/teroristicky-expert/ (accessed on 20 July 2021).

32. Ball, D.J.; Floyd, P.J. Societal Risk; Health and Safety Executive: Bootle, UK, 1998.

33. Ale, B.J.M. Tolerable or Acceptable: A Comparison of Risk Regulation in the United Kingdom and in the Netherlands. Risk Anal. 2005, 25, 231-241. [CrossRef] [PubMed]

34. Tarada, F.; Bopp, R.; Nyfeler, S. Ventilation and Risk Control of the Young Dong Rail Tunnel in Korea. In Proceedings of the 1st International Conference on Major Tunnel and Infrastructure Projects, Taipei, Taiwan, 22-24 May 2000.

35. Alwang, J.; Siegel, P.B.; Jørgensen, S.L. Vulnerability: A View from Different Disciplines. In Social Protection Discussion Papers and Notes; World Bank Group: Washington, DC, USA, 2001; p. 23304.

36. Weißhuhn, P.; Müller, F; Wiggering, H. Ecosystem Vulnerability Review: Proposal of an Interdisciplinary Ecosystem Assessment Approach. Environ. Manag. 2018, 61, 904-915. [CrossRef] [PubMed]

37. Takasawa, H. Update on the Rapid Environment and Health Risk Assessment Project; Working Group on Monitoring and Assessment: Helsinki, Finland, 2002.

38. Ministry of the Interior. Guideline for the Performance of Environmental Risk Assessment (within the Framework of Royal Decree 1254/1999 SEVESO II); Directorate General for Civil Protection and Emergencies: Madrid, Spain, 2003.

39. Scott, A. Environment-Accident Index: Validation of a Model. J. Hazard. Mater. 1998, 61, 305-312. [CrossRef]

40. Blazkova, K.; Danihelka, P. Methodology for Assessing the Impact of Accidents Involving a Dangerous Substance on the Environment (HEV Index II); Ministry of the Environment of the Czech Republic: Prague, Czech Republic, 2021.

41. Barrow, C.J. Environmental Vulnerability and Resilience. In The International Encyclopedia of Anthropology; Wiley-Blackwell: Oxford, UK, 2018. [CrossRef]

42. Holling, C.S. Resilience and Stability of Ecological Systems. Annu. Rev. Ecol. Syst. 1973, 4, 1-23. [CrossRef]

43. Folke, C.; Carpenter, S.; Walker, B.; Scheffer, M.; Elmqvist, T.; Gunderson, L.; Holling, C.S. Regime Shifts, Resilience, and Biodiversity in Ecosystem Management. Annu. Rev. Ecol. Evol. Syst. 2004, 35, 557-581. [CrossRef]

44. Scheffer, M. Critical Transitions in Nature and Society; Princeton University Press: Princeton, NJ, USA, 2009.

45. Wenning, R.J.; Apitz, S.E.; Kapustka, L.; Seager, T. The Need for Resilience in Environmental Impact Assessment. Integr. Environ. Assess. Manag. 2017, 13, 969-970. [CrossRef] [PubMed]

46. Mahmoudi, H.; Sayahnia, R.; Esmaeilzadeh, H.; Azadi, H. Integrating Resilience Assessment in Environmental Impact Assessment. Integr. Environ. Assess. Manag. 2018, 14, 567-570. [CrossRef]

47. Baho, D.L.; Allen, C.R.; Garmestani, A.S.; Fried-Petersen, H.B.; Renes, S.E.; Gunderson, L.; Angeler, D.G. A Quantitative Framework for Assessing Ecological Resilience. Ecol. Soc. 2017, 22, 17. [CrossRef] [PubMed]

48. Angeler, D.G.; Allen, C.R.; Garmestani, A.; Pope, K.L.; Twidwell, D.; Bundschuh, M. Resilience in Environmental Risk and Impact Assessment: Concepts and Measurement. Bull. Environ. Contam. Toxicol. 2018, 101, 543-548. [CrossRef]

49. Quinlan, A.E.; Berbés-Blázquez, M.; Haider, L.J.; Peterson, G.D. Measuring and Assessing Resilience: Broadening Understanding through Multiple Disciplinary Perspectives. J. Appl. Ecol. 2016, 53, 677-687. [CrossRef]

50. Moores, J.P.; Yalden, S.; Gadd, J.; Semadeni-Davies, A. Evaluation of a New Method for Assessing Resilience in Urban Aquatic Social-ecological Systems. Ecol. Soc. 2017, 22, 15. [CrossRef]

51. Matthews, E.C.; Friedland, C.J.; Orooji, F. Integrated Environmental Sustainability and Resilience Assessment Model for Coastal Flood Hazards. J. Build. Eng. 2016, 8, 141-151. [CrossRef]

52. Zhang, C.; Li, Y.; Zhu, X. A Social-Ecological Resilience Assessment and Governance Guide for Urbanization Processes in East China. Sustainability 2016, 8, 1101. [CrossRef]

53. IEC 61025. Fault Tree Analysis (FTA); International Electrotechnical Commission: Geneva, Switzerland, 2006.

54. IEC 62502. Analysis Techniques for Dependability_Event Tree Analysis (ETA); International Electrotechnical Commission: Geneva, Switzerland, 2010. 
55. Huang, W.; Zhang, Y.; Yu, Y.; Xu, Y.; Xu, M.; Zhang, R.; De Dieu, G.J.; Yin, D.; Liu, Z. Historical data-driven risk assessment of railway dangerous goods transportation system: Comparisons between Entropy Weight Method and Scatter Degree Method. Reliab. Eng. Syst. Saf. 2021, 205, 107236. [CrossRef]

56. Ak, R.; Bahrami, M.; Bozkaya, B. A Time-based Model and GIS Framework for Assessing Hazardous Materials Transportation Risk in Urban Areas. J. Transp. Health 2020, 19, 100943. [CrossRef] 